TRAMES, 2008, 12(62/57), 4, 450-469

\title{
THEORISING UNEVEN DEVELOPMENT: THE EPISTEMIC VALUE OF HISTORY AND COMPLEXITY IN THE STUDY OF ECONOMIC EVOLUTIONS
}

\author{
Valentin Cojanu \\ Bucharest University of Economics
}

\begin{abstract}
This work contrasts two self-declared 'ways of thinking' or 'grammars' - the high development theory (HDT) and the world-system analysis (WSA) - in the study of large-scale, long-term economic development and provides an epistemological appraisal which rests on two tenets. The first thesis says that both theories display striking explanatory similarities in terms of their subject matter (i.e. the rationale behind uneven development) in spite of clearly distinct modes of argumentation. The second thesis sets forth a criticism which points to the epistemological limits of both the mathematical construct of HDT and the historical arguments of WSA. This discussion raises a general problem of economic study, namely the directions along which the inquiry should proceed in order to achieve a coherent understanding of historical evolutions.
\end{abstract}

DOI: $10.3176 /$ tr.2008.4.06

Keywords: uneven development, economic change, epistemology, complexity

The work of scholars in the two traditions (i.e. quantitative and interpretive methodologies, N/A) seems to be divided by an unbridgeable epistemic gap. This impression seems confirmed by the informal attitudes of the researchers in question: quantifiers generally regard the interpretivists as hopelessly fuzzyminded and unscientific, and the interpretivists tend to dismiss the quantifiers as thick-headed and unsubtle (Sewell Jr. 2005:370).

\section{Introduction}

Uneven development is a result of historical evolutions relative to cumulative acquisition or deprivation of wealth usually assumed to occur within a large geographical area and over a sufficiently long period of time. The peculiarity of 
this subject matter is twofold. Firstly, its historical characteristic forces itself upon attention: the evolutions under consideration exhibit a certain degree of unpredictability in comparison with the regular character of natural phenomena. It was long remarked that economics does not have a model or logical mechanism to explain, "Why and how the huge economic inequalities between different countries have come to exist and why they tend to grow" (Myrdal 1957:152). By deciphering the code to human inequality the analyst is deemed to confront one of the most daunting scientific tasks, for there is "whatever the society and whatever the period, an insidious law giving power to the few, an irritating law it must be said, since the reasons for it are not obvious" (Braudel 1982:467).

Secondly, the topic provokes an elementary question: why should 'uneven development' require a different treatment as subject matter than, say, more neatly elaborated alike topics such as 'economic growth' or even 'development economics' per se? One simple answer would be that the unevenness seems to control, besides material prosperity, important characteristics of social life such as scientific recognition (Merton 1988), depletion of natural resources (Roberts and Emel 1992) or benefits of health and education (Neckerman and Torche 2007). Passing from Biblical judgment - for unto every one that hath shall be given, and he shall have abundance: but from him that hath not shall be taken away even that which he hath, Mathew 25:29 - to folklore - "For want of a nail, the shoe was lost; For want of a shoe [...] the kingdom was lost!" - to common wisdom - the poor stay poor, the rich get rich - there is a pervading popular sense of accidental, inevitable evolutions that govern people's life along imbalanced and probably undeserved destines.

Against this rather philosophical challenge, the scientific discourse has not been deprived of attempts that seem to have eventuated in settled analytical frameworks. Out of these traditions, two theoretical schemas stand out for their encompassing explanatory power: the economic modelling of 'high development theory' (HDT) and the analytics of historical social systems encapsulated by the 'world-system analysis' (WSA).

We argue that the epistemological basis of inquiry in the study of social evolutions can be enhanced by a contrasting perspective of these modes of argumentation. The choice for the two camps has been greatly facilitated by the visibility their leading proponents, Paul Krugman and Immanuel Wallerstein, respectively, enjoy in their own communities thanks to highly acclaimed pathbreaking approaches. Their epistemological ambitions are described in such terms as "a way of thinking" (Wallerstein 2004b:xii), "the essentials of the doctrine" (Krugman 1981), or, no less emphatically, "a common "grammar" (Fujita et al. 1999:xi). Krugman himself echoes the theoretical impact of his papers when he says, "My stuff is so incredibly innovative that people don't get the point" (quoted by Gans and Shepherd 1994). Paul Samuelson strikes a similar chord of praise by referring to him as "the rising star of this century and the next" (quoted by Martin and Sunley 1996). In its turn, the WSA is credited with providing "the most valid social scientific interpretations of the social world" (Sonntag 2003), while Eric 
Hobsbawm views Wallerstein as the "undoubted pioneer and most eminent practitioner of the 'world-systems' analysis to world development" (book cover endorsement to Wallerstein 2004b).

These common threads notwithstanding, radically opposing methodological approaches take the two visions apart. As Krugman repeatedly informs, the central feature of enquiry in his tradition - its differentia specifica - consists of the fundamental role formalism plays in guiding the investigation towards useful insights, "to help bridge the congenital communication gap between the social and physical sciences" (1994) and to put forth ideas "in the kind of tightly specified models... increasingly becoming the unique language of discourse of economic analysis" where "good mainstream" economics is equated to "full formal models" (2004). The world-system analyst is proposed in her turn a theoretical schema endowed with its own unit of analysis (the 'world-system'), language, method, and core assumptions (cf. Wallerstein 1974:349 and Wallerstein 2004b:17, 97ff.) in opposition to "the dominance of one particular mode of scientific method (which we may label simplistically 'Newtonian'), which has claimed to be the only legitimate mode of scientific behaviour" (Hopkins and Wallerstein 1996:7).

We are in the presence of two reputed bodies of knowledge which ignore one another by virtue of a self-professed claim to the correct approach. The more so intriguing, three similarities along their respective paths of inquiry startle any observer, namely the question they ask, the answer they find, and the wholehearted embrace of complexity studies' epistemic insights.

The next section proceeds with an overview of these similarities and attempts to dismiss one common view that there is "a tension between 'formal' and 'verbal' models of cumulative causation" (cf. Setterfield 2001). The discussion shows instead that the theory of uneven development is built on an equally shared core set of consolidated premises. On this basis, it is subsequently putting forth a criticism of the two bodies of knowledge. We propose a more radical observation which does not partake of those opinions that attempt to find a right balance between quantitative and interpretive methods in the study of historical evolutions. Economic modelling as much as historical social analysis may be misleading and at any rate futile provided that one continues to think of economic evolutions in the logic of 'physical' imagery of the natural systems as is suggested by their common recourse to complexity studies' language, mindset, and analytical discourse. Of particular interest here, the comparison between their argumentative modes reveals inconsistencies in terms of both subject matter and methodology and outlines a different epistemological context in the study of economic evolutions as hitherto suggested by the theory of uneven development. 


\section{The common language of uneven development}

The theory of uneven development is obviously inspired by uncontested evidence of increasing differentiation between aggregate economies in historical time. The rise and fall of cities, regions, countries, or empires has nurtured innumerable literary or scientific accounts alike. Maddison (2001) offers a glimpse of the world development with respect to two large aggregate economies, group A of developed countries (Western Europe, Western Offshoots - the United States, Canada, Australia and New Zealand - and Japan) and group B, the rest of the world. His data show that the income gap was almost null two thousand years ago, went up in favour of group B by year 1000, and from then on set gradually group A in advantage from 2:1 by 1820 to 7:1 in 1998 (27).

Even such a brief statistical account may suggest that large-scale, long-term evolutions inherently claim for a historical approach defined by two investigative questions: What does it take for a historical accident to propel some countries or regions on the path of development much faster than others? And, following Kaldor's (1960) search for "an alternative theoretical scheme", why things "happen in a certain way and why they do not happen in some other way?" (247) These are the very questions to which, as will be evident along the way, both modes of theorizing have proposed an encompassing set of answers that have made them so prominent.

In both perspectives, the theory of uneven development grew out of a familiar set of ideas built on the core concept of circular cumulative causation (CCC). Original streams of thinking are linked to the works of Thorstein Veblen, Allyn Young, Knut Wicksell, Nicholas Kaldor, Ragnar Nurkse, and Gunar Myrdal (Myrdal 1957:11, Martin and Sunley 1996, Berger and Elsner 2007). As might be expected of two nevertheless distinctive areas of research, specific intellectual legacy is claimed according to the epistemic core. In the HDT tradition, the list normally begins with the German school of location theory (Walter Isard, Alfred Weber, August Lösch, Walter Christaller, Johann Heinrich von Thünen) and ends with names like Robert Barro on convergence models, Robert Lucas Jr. on accumulation of knowledge, Brian W. Arthur on path dependence, and Krugman himself on the new economic geography (Martin and Sunley 1996, Martin 1999, Reinert and Riiser 2004). Though WSA represents the theoretical expression of its leading scholar (cf. Wallerstein 2004b), its intellectual roots admittedly are no less plentiful. Karl Marx, Sigmund Freud, Joseph Schumpeter, Karl Polanyi, Frantz Fanon, Fernand Braudel, and Ilya Prigogine, are "scholars who most fundamentally inspired the theoretical formulations and revisions of world-system analysis" (Sonntag 2003).

Further details on the resemblance of the analytical discourse may make up the object of a literary inquiry in itself, so strong is the parallelism between words, concepts, and ideas. We take up instead another stance and channel the discussion towards a different parallel, namely the common embrace of 'the science of 
complexity' - often used interchangeably with 'chaos theory' - a choice that is more fitting to shed light on the underlying rationale of uneven development.

The common language of cumulative causation has been a working hypothesis in mathematical writings at least since Jules Henri Poincaré (Science et méthode 1908) asserted:
"A very small cause which escapes our notice determines a considerable effect that we cannot fail to see, and then we say that the effect is due to chance... It may happen that small differences in the initial conditions produce very great ones in the final phenomena. A small error in the former will produce an enormous error in the latter. Prediction becomes impossible..." (quoted by Gleick 1987:321).

The mathematical branches of topology and non-linear dynamic systems, which led Poincaré to fame and inspired the above thoughts, as well as insights from then newly nascent physics of thermodynamics, have thus begun providing answers to a scientific study of chaotic behaviour of complex systems. Its mathematical apparatus' capability to substitute the rules of reversibility and determinism for those of irreversibility and randomness (Prigogine and Stengers 1984:8), as well as to depict 'out of chaos' emergence of "rich kinds of behaviour that never occur in linear systems" (Gleick 1987:24) has made a strong appeal to scholars in both traditions.

In trying to make sense of the logic of unpredictability that so manifestly affects development in its various materializations, both modes of theorizing have seized this methodological alternative that seems to reflect at best a twofold epistemological concern for (1) a valid replacement to justify their overt dissatisfaction against the mainstream view; and (2) an original, insightful conceptual thinking able to embody at once both causal explanation and accidental occurrences. For Krugman (2004), such fields of research as meteorology may bestow upon HDT useful investigative tools: "Yet in some ways the problems of economics and of social science in general are part of a broader methodological problem that afflicts many fields: how to deal with complex systems." In the interpretive discourse of WSA, the consequence of sudden discontinuities in longlasting evolutions also makes the analytical aspect fitting for the structures that underlie historical systems: "The outcome is not determined in advance, and hence cannot be predicted... there exist real choices that can be made?" (Wallerstein 1991).

A methodological predilection is nevertheless reflected in the way the two traditions attempt to elucidate the circumstances under which small differences give rise to large consequences over time. To be sure, the contradiction has been explicitly exposed by the very two camps.

According to Krugman (2004):

Economic theory is essentially a collection of models. Broad insights that are not expressed in model form may temporarily attract attention and even win converts, but they do not endure unless codified in a reproducible - and 
teachable - form... the influence of ideas that have not been embalmed in models soon decays.

In Wallerstein's words:

The quantifiability of data determined the choice of research problems which then determined the conceptual apparatuses with which one defined and handled the empirical data. It should be clear on a moment's reflection that this is an inversion of the scientific process. Conceptualization should determine research tools, at least most of the time, not vice versa (1974:8).

By implication, what one eventually gets consists of two distinct analytical frameworks erected on the common logic of historical accident and indeterminate evolutions. In quantitative tradition, the problem of inquiry arises as an intellectual artefact, under no spatial or temporal conditionality; for worldsystems analysts, the experience of uneven development is a dual reality, of systemic and of historical change. What the interpretive tradition describes as "some contextual whole" or "historical social system" (Myrdal 1957:164, Hopkins 1982, Wallerstein 1991), economic modelling takes for "symmetry between identical locations" (Fujita et al. 1999:9) and "prevalence of multiple equilibria" (Krugman 1994).

The mathematical models of complexity lend themselves so persuasively to the social study thanks to their feature to resemble real-world phenomena. For example, the asymptotical process intrinsically associated with chaos modelling shows that the developmental gaps widen until dampened by countervailing processes. In historical evolutions this belief in progress or in the ineluctability of catching-up embedded capabilities seems to be the analyst's will-o'-the-wisp. While it still remains subject to unpredictable evolutions, the modelled action of countervailing processes that close off the endless accumulation of advantage, allows for patterns of periodic reconfigurations of spatial economy in a way which seems to be hard to include, for example, in orthodox convergence models.

In another instance, the 'nonlinear' mechanism is apt to lead to a liferesembling representation by using difference instead of differential equations and hence enabling the process of evolution, be it natural, biological or social, to make jumps from state to state instead of changing smoothly (cf. Gleick 1987:61). Evolution proceeds through feedback loops, that continuously reinsert end results as new values of the parameters in the system, and is so able to produce novelty, of which no foreknowledge is possible. Further still, non-linearity leads to points of bifurcation, that is, points where there are two equally valid solutions for the equations, critical states of evolutions at which established configurations are no longer sustainable. Which equilibrium - read high or low level of development the economy ends up, runs the argument, depends on the previous history of the system, which in fact is a very technical issue reducible to the change of parameters and endless computer simulations. As the story goes on, the history so understood may illustrate at once a recurring narrative of punctuated equilibrium, of growth and decay, and an irreducible random element of historical accidents leading to long-run cumulative consequences. 
Even such a summarizing account of the use of complexity studies in explaining economic inequality would raise, from an epistemological point of view, a legitimate question: Why this quantitative mindset becomes also crucial for WSA, an approach which by definition explores historical social systems, and is thus meant to illuminate the "historical choice about which of the alternative paths will be followed, that is, what kind of new system will be constructed" (Wallerstein 2004b:76)? It is all the more interesting to discern the same logical threads given that early versions of the theory (e.g. Wallerstein 1974, Wallerstein 1980, Wallerstein 1982, Hopkins 1982) had been exposed without the accompaniment of any reference to quantitative work, less so to complexity studies.

Scattered analytical narratives have been used in the WSA tradition to depict a historically thick part of the reality as it became to emerge from the sixteenth century on: three different modes of labour control (i.e. forced labour, free labour, and an in-between form, share-cropping); increased dominance of long-distance trade as a source of "rapid accumulation of capital"; a geographical distribution of productive forces as a function of technology, possibilities of transport and communication, and political system; and the consequential emergence of a capitalist world-system distributed across three types of economies, a narrow, rich core, a middle zone - the semi-periphery - that enjoys partial prosperity at the risk of shortly possible decline, and, a vast, poor periphery. "Which areas play which roles is in many ways accidental" says Wallerstein (1974:355), but the overall picture is one of an economy-world which perpetuates inequality to the extent that the core-periphery relationship indicates the degree to which surplusvalue is unevenly distributed and cumulatively augmented in the direction of the core.

The thread of reasoning leads again to ascertain that the historical accident of the cumulative effect of small differentials would leave some regions in disproportionate (dis)advantage. Here is a WSA exemplar that concludes on the development gap between Eastern and Western Europe:

"One region has a slight edge over another in terms of one key factor, and there is a conjuncture of events which make this slight edge of central importance in terms of determining social action, then this slight edge is converted into a large disparity and the advantage holds even after the conjuncture has passed... The slight edge determined which of the two alternatives would prevail. At which point, the slight edge of the fifteenth century became the great disparity of the seventeenth and the monumental difference of the nineteenth" (Wallerstein 1974:98-99).

Later development of the theory (e.g. Hugon 1991, Wallerstein 2004b, Lee 2004) has however connected the logic of uneven development to complexities studies as fundamentally as its rival epistemology. In the new conceptualization, the peculiarity of historical systems implies that (1) they are not eternal and, consequently, "they had beginnings, lives during which they 'developed', and terminal transitions" (Wallerstein 2004b:18; emphasis added), and (2) the cyclical 
processes (medium-run trends, expansions and contractions) along with their crises "cannot be resolved within the framework of the system, but instead can be overcome only by going outside of and beyond the historical system of which the difficulties are a part" (Wallerstein 2004b:76).

The technical argument is rather unsophisticated. In Wallerstein's words:

A secular trend should be thought of as a curve whose abscissa (or x-axis) records time and whose ordinate (or y-axis) measures a phenomenon by recording the proportion of some group that has a certain characteristic. If over time the percentage is moving upward in an overall linear fashion, it means by definition (since the ordinate is in percentages) that at some point it cannot continue to do so. We call this reaching the asymptote, or 100 percent point... This means that as we solve the middle-run problems by moving up on the curve, we will eventually run into the long-run problem of approaching the asymptote (2004b:31).

The intriguing observation that one can be provided with a quasi-identical explanation by two opposed modes of argumentation will be subsequently followed through.

\section{Understanding historical evolutions: a critique of the theories of uneven development}

Reciprocal antinomy aside, the two modes of theorising have not been spared external criticism either. For example, HDT proposes to geographers a model of development that embodies "trivial" empirical applications, results "not particular novel", and analytics "too abstract, over simplified and too idealised" (Martin 1999), while WSA retains much vagueness - "the term world system was clumsy and obviously inadequate" (McNeill 2005:154), exhibits a deterministic vision of historical processes (Sewell Jr. 2005:85-88), and, adding insult to injury, remains virtually ignored by contemporary similar quests (e.g. "The Other Canon"; Reinert and Riiser 2004, Harvey 2006, Hindess 2007).

The ensuing argument will have to admit that this criticism is in part true. Our perspective is grounded on the observation that the subject matter, as well as the method of both theories, is crippled by inconsistency if one follows the logic of complexity in historical processes to its ultimate consequences. The point is subsequently advanced along the lines of a discussion relative to the mathematical assumptions and interpretation of development in the HDT tradition, and then to the interpretive limits of the WSA.

\subsection{A discussion on quantitative theorising}

In perfect confidence of the explanatory power of the natural imagery of chaos theory, Gleick narrates how a scientist of life sciences chooses the analytical toolkit: 
A physicist... finds the right equations from the first principles. Then he solves the equations, if he can. A biologist, by contrast, could never simply deduce the proper equations by just thinking about a particular animal population. He would have to gather data and try to find equations that produced similar output (1987:60; emphasis added).

One defining characteristic of economic modelling is the belief that the logic of mathematical formalism resembles the real world, of biotic populations, as well as of human affairs; what is theoretically possible is of necessity a fair description of economic reality: "Economists insist that their equations actually do say something about the real world" (Krugman 1998).

Economic systems are indeed prone to unpredictable behaviour, runs the argument of HDT, due to the existence of economies of scale. An early version of the theory (Krugman 1981) proves that 'uneven development' is a necessary outcome in a two-country model of capital accumulation and growth: on the presumption that the industrial sector exhibits increasing returns to scale, "an initial discrepancy in capital-labour ratios between the two countries will cumulate over time, leading to the division of the world into a capital-rich, industrial region and capital-poor, agricultural region."

The availability of new modelling techniques for non-linear dynamic systems has made possible a more realistic, detailed view of the economic systems that translates in fact as an ever more challenging mathematical construct. In more developed variants (e.g. Fujita et al. 1999, Krugman 2004), the economic descriptions can barely be visualised or theoretically assembled unless a computer simulation emulates a real-world situation.

In a typical simulation of, say, the three-region case, the computer run would yield four equilibria, where in three all manufacturing is concentrated in one location and one where there is an equal distribution of manufacturing across locations. Where have these outcomes resulted from? It turns out that the answer is but a figment obtained for the most interesting range of parameters, which for that matter were only three, i.e. the elasticity of substitution among products in the manufacturing sector, set for this example at 4; the share of manufactures in expenditure, set at 0.2 ; and the transport cost between any two locations, set at 0.4 (cf. Krugman 1994).

It is only now that details of economic evolutions enter the scene. The location of economic activities is at the behest of the simultaneous work of centrifugal and centripetal forces, which in their turn are determined by a complex combination of variable factors. For example, the cost of transportation may be conducive both to a greater mobility of factors or to a locally based economic development, as the availability of pools of knowledge and technological spillover may reinforce or abate the trend when abundant or scarce, respectively. The economic landscape thus changes in unpredictable configurations from path-dependant and locked-in processes to endlessly agglomerative processes and vice versa. Prosperity (poverty) follows the inherently superior (inferior) activities in terms of generating increasing returns. 
The preceding discussion has shown that the essential feature and minimal assumption of cumulative causation consists of the emphasis on economies of scale. That income-generating activities possess distinct intrinsic capabilities to spawn increasing returns to scale may indeed be a source, the source, of exponential differentiation, but this need not be the case, or the direction of causal link. That is why our contention to economic modelling regards its inbuilt capability to provide a 'historical' account of equilibrium and not of development per se, with a resulting significant loss of critical social detail along the way.

One may nevertheless notice a nuance of interpretive concession. As at any moment in time the future course of diverging evolutions is explained by a set of initial conditions, and the latter may be conceived in terms of historical specificity. "Whether one prefers to explain the greater initial accumulation of capital in one region by the slave trade or the Protestant ethic, this is a model in which small beginnings can have large consequences" (Krugman 1981). By implication, any other historical set of circumstances could thus replace economies of scale as a model's premise as long as, of course, they could be made tractable in quantitative terms.

It may be also retorted that the choice of equations' parameters in the first place has been indeed a case of economic appraisal of how the world works. This assertion is already weakened by an assumed Friedmanian type economics which advocates an analysis on its capability to predict evolutions irrespective of the realism of its assumptions. "A set of clearly untrue simplifications...dictated partly by guesses about what is important, partly by the modelling techniques available" (Krugman 2004). For those insensitive to these presuppositions, it could be further assumed that the formal model may turn someday into a more realistic image of the world based on similarly more realistic assumptions by virtue of increased computational complexity and continued recalibration.

For this reason, our counterargument that critical details in the representation of subject matter get lost in the modelling approach apparently becomes superfluous. This is not however the case precisely because it is the very logic of formalism and not its analytical capability which is of little relevance in historical contexts. Its main explanatory power is based on in-built 'predictive' characteristics of the models, which misleadingly takes mathematically necessary outcomes for historically possible economic evolutions.

Consider again Gleick's narrative of the choice of method. The mathematical parameter, say $x$, lends itself to interpretation across scientific disciplines exclusively according to the researcher's modelling needs. The amount of heating or of friction in physical systems may correspond in biology to fecundity of the fish, the propensity of population to boom and to bust, concentration of substance, whereas in economics metamorphoses into concentration of manufacturing or of employment in a given region or industry. What is used to describe characteristics of population like birth rate, death rate, or the amount of resources available becomes characteristics of local levels of economic activity such as migration, share of income spent locally, 
size of market or the region's 'export base' (cf. Gleick 1987:60, 63, Prigogine and Stengers 1984:194, 160, Fujita et al. 1999:27-28).

By the same token, the computer simulation in economics will as meaningfully describe the successive evolutionary steps of the process dependent on some parameter $x$ as in physics or in biology. The isomorphism translates from cases of climatic fluctuations or ecological evolution to spatial configuration of larvae of coleopteran, construction of a termites' nest or arrangements of a population of macromolecules to examples of spatial configuration of economic activities or of emergence of dominant cities (cf. Prigogine and Stengers 1984:181, 190, 194, Fujita et al. 1999:27-28) according to the technique of choice. The logic of reasoning is of purely technical character: the degree of nonlinearity and hence of unpredictability rests on the abstract manoeuvring of the various levels of parameter $x$.

The emerging picture of evolution includes, in truth, explanations of "the nature of the positive feedback that can lead to self-reinforcing growth or stagnation" (Krugman 2004) but only for a snapshot of its temporal sequence. Capturing historical growth and development processes in 'formal' models does not however allow escaping the trap of linear chronology. Evolutions cannot be accurately explained along the widening gap curves: the increasing complexity of production and social life in general is neither unambiguously beneficial nor harmful to growth, nor do circumstantial factors inevitably and irrevocably doom an economy to a future of relative decline or progress.

To bring the argument more forcefully to light, let us take an example fully disclosed in its most significant details by various researches. The Dutch economy was for fairly long time - ca. one hundred years - the leading force of economic progress in the sixteenth and seventeenth centuries. This achievement was made possible by a unique combination of economic capability "in the historically oldest form of food production, that of gathering, in this case the gathering of fish" (Wallerstein 1980:39) and a shrewd control of power in the Baltic trade. The whole set of economic activities - fishing industry, agriculture, livestock husbandry, textiles, shipbuilding - constituted itself indeed in a favourable environment, with its forward and backward linkages, but only a peculiar contingency embodying the circumstances of political power and economic tradition triggered the boom. The enviable naval position in the Baltic Sea in fact reinforced the advantage of the shipbuilding and eventually placed the Dutch "in the happy circumstance of the spiral effect: circular reinforcement of advantage" (Wallerstein 1980:40).

The Dutch economy example is just an instance of the causal sequence that connects the monopoly power of "trade circuits and communications" (Braudel 1982:153) to ordinary episodes of economic life. A distinct implication of this historical account is that specialization no longer appears as a mere result of the interplay of maximizing decisions in a constrained environment. It even comes out that its relevance in determining a certain course of evolutions in the long term is virtually nullified as long as prosperity has recurred mainly in association with the 
influence and political power of deeds of trade. What conventional economic theory expounds as reciprocal benefits of free trade, the historical fact describes rather as an indeterminate interplay of historical circumstances. In the light of historical evidence, the famous Ricardian example of Anglo-Portuguese trade becomes an historical outcome of "an inheritance, the consolidation, historically achieved over time, of a situation dating from some earlier period... established progressively as a chain of subordinations" along which "Portugal, once a rich country... had been pushed towards the other direction [of unequal exchange]" (Braudel 1984:48).

The supposition of economies of scale or of any other tractable economic fact as one all-covering causality is further weakened by other works that place cumulative advantage within a rather diverse range of sources besides power relations. For instance, Neckerman and Torche (2007) and Berger and Elsner (2007) emphasize the circular cumulative causation of specific organizational contexts, whereas Martin (1999), in the same vein, enlists a host of important locally varying factors (e.g. infrastructure, state spending and intervention, regulatory arrangements, human capital formation) to make up for what geographers call "institutional thickness".

A claim to valid interpretation is also advanced by the literature that ascribes a role for "growth spurts" (Fearn 2004) or "power jumps" (Mann 1986:525) as isolated or unique economic episodes instrumental in generating positive feedback over time (se also Martin and Sunley 1996, Nayyar 2006). Economic externalities may become indistinguishable in a socio-cultural context that is the millennia receptor of human breakthroughs ranging from animal domestication and iron smelting to satellite television and digitalization of the arts.

Even the literature sympathising with quantitative techniques has to concede a sort of middle-range theorising in favour of historical interpretation. The latter may include concepts like "countervailing and supporting changes of cumulative causation" (Myrdal 1957:13, 20), "attitudes to risk-taking and money-making" (Kaldor 1960:228) or "entrepreneurial response" (Setterfield 2001). The role of increasing returns, of no negligible importance in ceteris paribus-based abstract reasoning, goes nevertheless almost unnoticed within a historically embedded sociality which eventually explains why "spatial agglomerations occur in particular places and not in others" Martin (1999).

Our thesis therefore implies that quantitative theorising cannot but lead to results expected by virtue of the in-built features of the model itself. This is just a restatement of the trivial evidence that, by their very logic, mathematical propositions - within the presuppositions underlying their construct - may well prove infallible as the truths are logically deduced from premises which are themselves definitions. For event regularities and law-like phenomena, this approach could indeed make sense, but as will become evident in the ensuing discussion of the interpretive thinking, they occupy but a secondary position in the economic study. 


\subsection{Discussion on interpretive theorising}

The paired mindset of time and space, of TimeSpace and world-system bequeaths the discourse on development one of the most important conceptual legacies in the WSA tradition. It brings in a view of society that evolves in social temporality, as a historical system in a particular social space, at a particular social time. Specific terminology is used to reveal the fabric of social temporality in terms like "layers" (Wallerstein 1974:86), "chains" or "series" (Braudel 1981:560), "sets" or "orders" (Braudel 1984:70), "vectors" (Hopkins and Wallerstein 1996:2), "structures/ categories" (Braudel 1996:28, Wallerstein 2000), or, in a summative expression, "overlapping histories, developing simultaneously" (Fernand Braudel quoted by Wallerstein 1980:20). No matter which linguistic choice, the emerging picture is that of social developments evolving on a plateau of concurrent sequences of events, and possibly in different historical times.

The exercise to enlist these sequences seems at once both familiar and novel for they continue to resemble the usual vocabulary of social sciences, whereas nevertheless serving a different methodological purpose. For example, serial history grew out precisely of the analytics of "series" - i.e. separate entities of social fact organized like macroeconomic series of prices, wages, demography, trade cycles etc. - and served the purpose of introducing history to quantitative study. As has been suggested, the tack here is different. In our view, large-scale, long-term evolutions cannot be in a meaningful way subjected to scientific inquiry unless understanding of the various sequences at work holds centre stage in a history-laden version of the theory. In this sense, we concur with those views that subordinate the existence of various simultaneous histories to "the overarching structure of the social whole" (Hindess 2007) and channel the debate specifically in giving reasons against the claim that WSA becomes relevant exclusively within "the boundaries of the historical system in general" (Wallerstein 1991).

"One cannot analyze social phenomena unless one bounds them in space and time", asserts Wallerstein (1980:245), and Lee (1996) reiterates the assumption with a slight nuance, the WSA is "temporally bounded, and spatially delimited (but expanding)."

From our point of view, this presupposition introduces unnecessary epistemological constraints. If the conjecture of the existence of social temporality is right, the normal corollary then is that the issues of starting and of terminal points in social evolutions are a partial, and possibly incorrect, description of reality. What can make the uneven development discourse retain its analytical consistency would force us to think of variable instead of bounded spatial coordinates and continuous instead of discontinuous temporal coordinates. This ultimate consequence seems the more valid as the logic required by the historical nature of evolutions implies that no one sequence, be it capital accumulation, economies of scale or division of labour, seems to dominate the outcomes in spite of the contrary claim of the two modes of theorising. 
The natural onset to work out our conjecture in detail is the problem of spatial-temporal boundaries in historical systems as presented in one apodictic tenet:

In the late fifteenth and early sixteenth century, there came into existence what we may call a European world-economy... The starting points and ending points vary according to the national perspective from which one views the century. However, for the European world-economy as a whole, we consider 1450-1640 the meaningful time unit, during which was created a capitalist world-economy (Wallerstein 1974:15, 68).

Furthermore, in a kind of inescapable if unpredictable destiny, "there must come a point when the trends create a situation in which the cyclical rhythms are no longer capable of restoring long-term (relative) equilibrium" and, at this turning point, the system is replaced by "one or more alternative successor systems" (Hopkins and Wallerstein 1996:8).

The whole thesis puts forth a compelling argument, cogently disguised in the language of complexity studies: a space of development (the European worldeconomy primarily understood as "parts of Europe and the Americas", Wallerstein 2004b:23) gives rise to divergent evolutions (increasing gaps of well-being) within the duration of a particular historical system (the world-system). Let us think about this particular spatial-temporal conditionality in the same way the WSA suggests, as multiple sequences of events.

There should be little ambiguity: the modern world-system is the story "analytical history" - of a singular phenomenon, "the theory of capitalist development as part of a larger theory of sociohistorical change" (Wallerstein 1980:8, Wallerstein 2004a:91). With this caveat in mind, we may be nevertheless able to position our historical telescope to other possible Europes of the same time in contrast only to modern Europe. The other Europes, for which capitalism is a form that, like so many other forms, may or may not be inevitable, may be thought of as any other geographical-historical configuration, each one being the result and the origin of significant economic evolutions themselves at different meaningful, intertwining geographic and temporal scales, ranging from global phenomena to individual histories.

Consider the global scale first. Neolithic or the agricultural revolution seems to be an undisputed temporal reference as to humankind's original attempt to escape backwardness. For Wallerstein (1974:3) the next great watershed becomes manifest at the creation of the modern world. It was only then that a circumstantial concurrence of propitious conditions for the international division of labour resulted in wealth accumulation through long-distance trading and market-based exchanges.

For other scholars, this exact timing may be less relevant as they look at social temporality through different lenses. For Clark, "the accidents of institutional stability and demography" (2007:11) prompted economic progress on a spiralling and diverging path no sooner than the times of Industrial Revolution. McNeill sees the rise of the world system about the time of the Christian era (ca. 1000 A.D.). 
Not only was an enduring "market-regulated behaviour" already in place by that time (1980:37), but also, the crux of his view, "human populations had adjusted to the confluence of the various infectious diseases that in earlier times had developed differently in different parts" (1976:132).

Braudel substantially relaxes the assumption of any boundary by arguing in favour of the existence of "several world-economies that coexisted" by the Middle Ages and even in antiquity (Braudel 1977:83), as well as of a "first worldeconomy ever to take shape in Europe, between the eleventh and thirteenth centuries" (Braudel 1984:92). He even advances a radical view of the study of the elementary constituents of economic evolutions such as production, exchange or consumption by arguing that they "do not depend either on ancient or recent choices made by a particular civilization... or on a past which continues to influence everyday life. These elementary rules have no frontiers" (Braudel 1982:114).

At smaller scales of human evolution, one may similarly encounter sequences of events in diverse manifestations, which individually converge to position social temporality at the behest of indeterministic behaviour. For Braudel, "the weapons of domination" so forcefully permeated the social fabric that "a few wealthy merchants... could throw whole sectors of the European or even world economy into confusion, from a distance" (1981:24). At the other extreme, ordinary people may become only more estranged to social realities and got lost "in the dirty and complicated worlds of governmentality and political society" (Partha Chatterjee quoted by Corbridge 2007).

It seems obvious that the sixteenth century and some further bound cannot be relevantly posited as milestones except for inducing a causal mechanism predominantly based on capital accumulation. Once one also begins to accept other broad sequences, the resulting rationale embodies a vision of unbounded social temporality which fundamentally rests on the recognition of multiple, concurrent equivalent sequences of historical events.

It goes much beyond the scope of this paper to sketch out an analytical resolve of the problem of sequences. One may however point to an ad hoc definition which bears the WSA imprint: sequences are "complexes of processes that provide the continually evolving structured frameworks within which social action has occurred [and] bear within them the processes by which they get transformed into other structures/categories" (Hopkins and Wallerstein 1996:2, Wallerstein 2000).

What this definition and our previous discussions suggest is that, over long periods of time and across large geographical areas, socio-economic evolutions materialize in unpredictable phenomena at the confluence of multiple, concurrent factors. Uneven development in our case is such a result of historical influences originating in capital accumulation, capital/labour ratios, institutions, resource endowments, or economic externalities. Scholars familiar with the topic have convincingly made a case for a more extended list that should also include climatic fluctuations (Gustaf Utterström quoted by Wallerstein 1974:34), "critically 
important epidemiological breakthroughs" (McNeill 1976:3), migration (Nayyar 2006), "the taxation crisis of patrimonial bureaucracy" (David Lockwood quoted by Wallerstein 1974:29), or the underlying structures of civilizations like religious beliefs, attitudes to death, work, pleasure and family life (Braudel 1996:28). If the researcher had to take on a different task he would necessarily attempt to build up a different list of relevant, manifest, long-lasting sequences of events. The set will change composition according to various analytical contexts and it will come then not much as a surprise to rely on similar interpretations, say externalities as an enduring feature of social segregation. After all, the study of economic phenomena must share a common epistemological background.

At the same time, short temporal events seem to be more easily framed in lawlike trends and regularities, in narrower sequences. In contrast to the broad one, the narrow occurrence is determinate, predictable, and possibly quantifiable. When a region of development begins to coagulate ever more productive factors, the visible result may be indeed a direct consequence of such impersonal, familiar drivers as efficiency (cost minimization) or market exchange (opportunity cost). Nevertheless, the more one attempts to make sense of these processes at historical scale, the less understandable is the causal sequence. It is in this sense, of meaningful social evolutions, that we should interpret the broad and the narrow, the universal and the particular, the recurrent and the accidental event in cultural rather than natural imagery.

\section{Concluding remarks}

For analysts who deal with the logic of reinforcing and cumulative advantage in historical processes any methodological squabble between HDT and WSA traditions should be simply seen as irrelevant. Both theories present a remarkable resemblance relative to the broad structure of their causal mechanism.

Here is a summarized version of the received view of uneven development along four explanatory modules equally advocated by the two traditions:

(1) Development is an inherently indeterminate process that manifests itself through an arbitrary mechanism of cumulative (dis)advantage. Both chance and circular causation perpetuate a seemingly uncontrollable tendency leading to either prosperity or poverty.

(2) The spatial pattern of world economy is usually treated in a terminology which prefers indefinite geographical areas to national entities. Different configurations of two, three or more areas of development set in motion a spatial arrangement of economies with its own in-built dynamics which engenders unpredictable temporal sequences of developed and less developed areas. 
(3) Though the analysis portends to take differences between macro economies as the basic scenario, asymmetrical development replicates itself along the whole range of human experiences according to the same rationale. We thus encounter widening gaps of prosperity specific to individuals, occupations (e.g. industry vs. agriculture, trade vs. industry and agriculture), areas within homogeneous zones of development, or other sub-regional entities like cities.

(4) Self-reproducing inequalities are the necessary result of a very visible, identifiable mechanism, say the accumulation of capital, even if the emergence of the contingent trigger in a certain place at a certain time could be hypothesised in ex post theorising only.

On the other hand, it might be assumed that, in a more historically based study of economic phenomena, unpredictability is essentially linked to the randomness of the overlapping sequences rather than a priori centres of agglomeration (attractors) or dissipation (bifurcations), or any other possible natural imagery. The sequential causality implies a more radical view on unpredictability: it not only regards future events, but also past events. In a phrase attributable to Mark Twain, it is hard to make predictions, especially about the past.

Historical specificity embedded in the subject matter (e.g. uneven development) builds up the argument from broad historical sequences (e.g. capital accumulation, control of power) to narrower and subordinate, explanatory sets of events (e.g. capital-labour ratios, trade cycles) to the least historical events, those historical particulars, that recur more or less identically over time, such as pricing in the period of severe drought or selling under conditions of monopoly, and which are characteristic of a market economy in this very narrow sense.

"Where chaos begins, classical science stops," said Gleick (1987:3), whereby pronouncing a radical departure from a resolutely deterministic approach to physical science. Soon after, scholars from various fields, including social science took in earnest his predicament, for better or for worse. It is much in the spirit of this paper to conclude by saying, where socio-economic evolution begins, natural imagery withers. The logic implied by this paper suggests that we do not possess an explanatory framework akin to natural events when inquiring about economic phenomena, but we do know what to look for: a historical toolkit that combines understanding of sequences and techniques for the particulars.

\section{Acknowledgements}

The paper was presented at the Association for Heterodox Economics 10th Anniversary Conference, Anglia Ruskin University, Cambridge, UK, Wednesday 2nd-Sunday 6th July 2008. I received helpful feedback from participants at the Fernand Braudel Centre at State University of New York (Binghamton) where a 
draft version of the paper was presented on November 14th, 2007. Financial support from Fulbright Commission is gratefully acknowledged for being instrumental in preparation of library research at Bloomsburg University of Pennsylvania (USA) at the time of writing.

\author{
Address: \\ Valentin Cojanu \\ Academia de Studii Economice \\ Piata Romana 6 \\ Bucuresti 010374, Romania \\ E-mail: cojanu@ase.ro
}

\title{
References
}

Berger, Sebastian and Wolfram Elsner (2007) "European contributions”. Journal of Economic Issues 41, 2, 529-537.

Braudel, Fernand (1977) Afterthoughts on material civilization and capitalism. Baltimore: The Johns Hopkins University Press.

Braudel, Fernand (1981 [1979]) Civilization and capitalism 15th-18th century. Vol. 1. The structures of everyday life. New York: Harper \& Row.

Braudel, Fernand (1982 [1979]) Civilization and capitalism 15th-18th century. Vol. 2. The wheels of commerce. New York: Harper \& Row.

Braudel, Fernand (1984 [1979]) Civilization and capitalism 15th-18th century. Vol. 3. The perspective of the world. New York: Harper \& Row.

Braudel, Fernand (1994 [1963]) A history of civilizations. Allen Lane: The Penguin Press.

Clark, Gregory (2007) A farewell to alms. A brief economic history of the world. Princeton: Princeton University Press.

Corbridge, Stuart (2007) "The (im)possibility of development studies". Economy and Society 36, 2, 179-211.

Fearn, Robert M. (2004) “A note on rapid economic development”. South Eastern Europe Journal of Economics 2, 2, 7-17.

Fujita, Masahisa, Krugman Paul, and Anthony J. Venables (1999) The spatial economy: cities, regions, and international trade. Cambridge: The MIT Press.

Gans, Joshua S. and George B. Shepherd (1994) "How are the mighty fallen: rejected classical articles by leading economists". The Journal of Economic Perspectives 8, 1, 165-179.

Gleick, James (1987) Chaos: making a new science. New York: Viking.

Harvey, David (2006) Spaces of global capitalism: towards a theory of uneven geographical development. London: Verso.

Hindess, Barry (2007) "The Althusserian moment and the concept of historical time". Economy and Society $36,1,1-18$.

Hopkins, Terence K. (1982) "The study of the capitalist world-economy. Some introductory considerations". In World-systems analysis: theory and methodology, 9-38. T. K. Hopkins and I. Wallerstein, and Associates, eds. Beverly Hills: Sage Publications.

Hopkins, Terence K. and Immanuel Wallerstein (1996) "The world-system: is there a crisis?". In The age of transition: trajectory of the world-system 1945-2025, 1-10. T. K. Hopkins and I. Wallerstein et al., eds. London: Zed Books.

Hugon, Philippe (1991) "L'économie du développement, le temps et l'histoire" Revue économique $42,2,339-364$.

Kaldor, Nicholas (1960) Essays on economic stability and growth. Glencoe, Ill.: The Free Press of Glencoe. 
Krugman, Paul (1981) "Trade, accumulation, and uneven development" Journal of Development Economics 8, 2, 149-161.

Krugman, Paul (1994) "Complex landscapes in economic geography" The American Economic Review 84, 2, 412-416.

Krugman, Paul (1998) "Two cheers for formalism”. The Economic Journal 108, 1829-1836.

Krugman, Paul (2004) "The fall and rise of development economics". Retrieved from http://web.mit.edu/krugman/www/dishpan.html [July 2007].

Lee, Richard E. (1996) "Structures of knowledge". In The age of transition: trajectory of the worldsystem 1945-2025, 178-206. T. K. Hopkins, I. Wallerstein et al., eds. London: Zed Books.

Lee, Richard E. (2004) "Complexity studies". In Overcoming the two cultures: science versus the humanities in the modern world-system, 107-117. R. E. Lee and I. Wallerstein, eds. Boulder: Paradigm Publishers.

Maddison, Angus (2001) The world economy: a millennia perspective. Paris: OECD.

Mann, Michael (1986 [1995]) The sources of social power. Vol. 1. A history of power from the beginning to A. D. 1760. Cambridge: Cambridge University Press.

Martin, Ron (1999) "The new 'geographical turn' in economics: some critical reflections". Cambridge Journal of Economics 23, 1, 65-91.

Martin, Ron and Sunley Peter (1996) "Paul Krugman's geographical economics and its implications for regional development theory: a critical assessment". Economic Geography 72, 3, 259292.

McNeill, William H. (1976) Plagues and peoples. New York: Doubleday.

McNeill, William H. (1980) The human condition: an ecological and historical view. Princeton: Princeton University Press.

McNeill, William H. (2005) The pursuit of truth: a historian's memoir. The University Press of Kentucky.

Merton, Robert K. (1988) "The Matthew effect in science, II: cumulative advantage and the symbolism of intellectual property". Isis 79, 4, 606-623.

Myrdal, Gunar (1957) Rich lands and poor: the road to world prosperity. New York: Harper \& Row.

Nayyar, Deepak (2006) "Globalisation, history and development: a tale of two centuries". Cambridge Journal of Economics 30, 137-159.

Neckerman Kathryn M. and Florencia Torche (2007) "Inequality: causes and consequences". Annual Review of Sociology 33, 335-357.

The other canon: reconstructing the theory of uneven economic development. Retrieved from http://www.othercanon.org/papers/index.html [8 Nov. 2007].

Prigogine, Ilya and Isabelle Stengers (1984) Order out of chaos: man's new dialogue with nature. Toronto, Bantam Books.

Reinert, Erik S. and Vemund Riiser (2004) Recent trends in economic theory - implications for development geography. (STEP Group Report Series, R-14.) Oslo.

Roberts, Rebecca S. and Jacque Emel (1992) "Uneven development and the tragedy of the commons: competing images for nature-society analysis". Economic Geography 68, 3, 249-271.

Setterfield, Mark (2001)" Cumulative causation, interrelatedness and the theory of economic growth: a reply to Argyrous and Toner". Cambridge Journal of Economics 25, 1, 107-112.

Sonntag, Heinz R. (2003) "World-System analysis as critical theory for the 21 st century". In Emerging issues in the 21 st century world-system. Vol. 2, 239-246. W. A. Dunaway, ed. Westport, Conn.: Greenwood Publishing Group.

Sewell Jr., William H. (2005) Logics of history: social theory and social transformation. Chicago: The University of Chicago Press.

Wallerstein, Immanuel (1974) The modern world-system: capitalist agriculture and the origins of the European world-economy in the sixteenth century. New York: Academic Press.

Wallerstein, Immanuel (1980) The modern world-system II: mercantilism and the consolidation of the European world-economy, 1600-1750. New York: Academic Press.

Wallerstein, Immanuel (1982) "World-system analysis: theoretical and interpretative issues". In World-systems analysis: theory and methodology, 91-103. T. K. Hopkins, I. Wallerstein, and Associates, eds. Beverly Hills: Sage Publications. 
Wallerstein, Immanuel (1991) "A theory of economic history in place of economic theory?". Revue économique 42, 2, 173-180.

Wallerstein, Immanuel (2000) "The development of an intellectual position". Retrieved from http://www.yale.edu/sociology/faculty/pages/wallerstein/ [8.10.2007].

Wallerstein, Immanuel (2004a) The uncertainties of knowledge. Philadelphia: Temple University Press.

Wallerstein, Immanuel (2004b) World-systems analysis: an introduction. Durham: Duke University Press. 